\title{
Colección hemerográfica local digital de las bibliotecas públicas de la provincia de Barcelona
}

\author{
Por Glòria Pérez-Salmerón y Anna M. Surroca Carrera
}

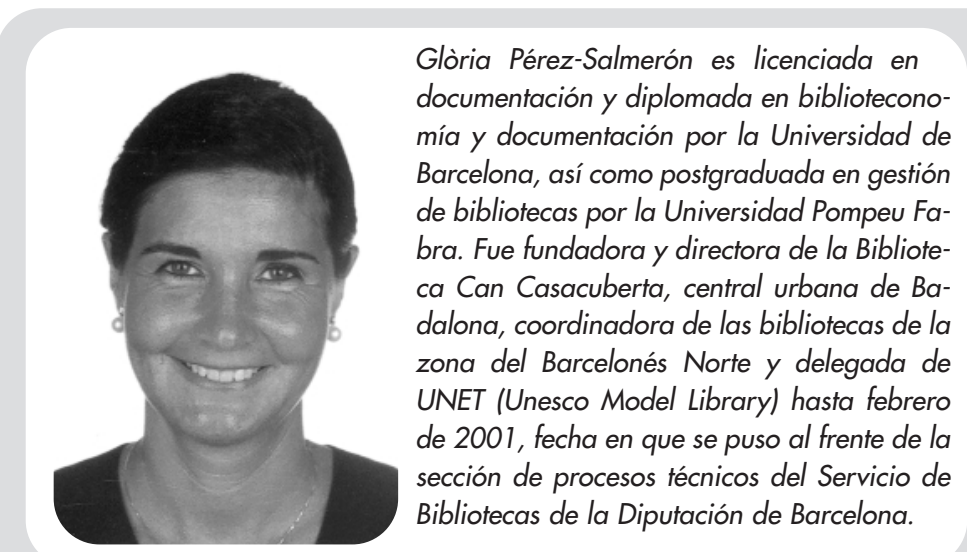

Palabras clave: Biblioteca pública, Digitalización, Colección única, Contenidos locales, Indización, Derechos de autor, Interfaz web, Ocr.

Title: The digitised local periodical collection of the public libraries of the province of Barcelona

Abstract: The Public Library Service of the Diputación de Barcelona (Provincial Council) is carrying out a project to digitise historical periodicals of local interest deposited in diverse municipal libraries of the province's network. In addition to the physical preservation of these unique collections, the intention is to index the issues and make the data available through the Service's web page. The article discusses the phases of the project, the work procedures that have been developed, the economic investment that this endeavour represents the economical forecast for 2004, as well as the future outlook of the provincial digital library.

Keywords: Public libraries, Digitisation, Rare collections, Local contents, Indexing, Copyright, Web interfaces, OCR.

\section{LA BIBLIOTECA PÚBLI-}

CA a lo largo de su existencia ha ido recogiendo, conservando y organizando lo que hemos llamado la colección local con contenidos relacionados con su área de influencia. Generalmente está compuesta por monografías, revistas, folletos y otros materiales que se han publicado en el área geográfica donde está ubicada, que tratan de ese territorio, o que han sido producidos por autores locales, nacidos o acogidos en la zona. De todos es sabido la importancia de poder conservar y difundir esta colección local, que a menudo se ha convertido en "colección única".
Resumen: El Servicio de Bibliotecas de la Diputación de Barcelona está llevando a cabo un proyecto de digitalización de las publicaciones periódicas históricas de interés local depositadas en diversas bibliotecas municipales de la red provincial. Consideradas colecciones únicas, se suma al propósito de preservación física, el de indización y de ponerlas accesibles a través de su página web. El articulo recoge las fases del proyecto, el proceso de trabajo que se ha ido desarrollando, la inversión económica que ha supuesto, la previsión para el 2004, así como la perspectiva de futuro de la biblioteca digital provincial.

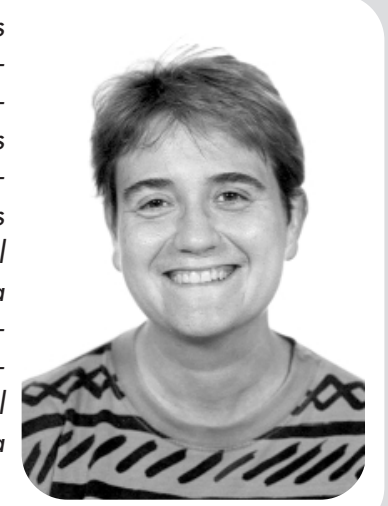

Anna M. Surroca Carrera es licenciada en filología románica, diplomada en biblioteconomía y documentación, ambas por la Universidad de Barcelo na y postgraduada en nuevas tecnologías para la gestión y e acceso a la información por la Fundació Politècnica de Cata lunya. Dirige la Unidad de Tec nologías de la Información de Servicio de Bibliotecas de la Diputación de Barcelona.

El entorno digital debilita la idea de la biblioteca como única propietaria de la colección situada físicamente en un espacio concreto, permitiéndonos visualizarla dentro del contexto actual de globalización (de relaciones económicas y culturales en general) en este nuevo entorno digital. Esto la ha empujado a convertirse en un agente activo que potencia los contenidos de carácter local adquiriendo, lo local, un papel de mayor importancia. El hecho de poder disponer de la "colección única" sitúa la biblioteca en una posición de privilegio y de nuevas oportunidades.

Con la voluntad de preservar y ofrecer acceso al texto completo de las publicaciones periódicas de ámbito local, el Servicio de Bibliotecas de la Diputación de Barcelona inició en 1999 un proyecto de digitalización de revistas, diarios y boletines de los documentos originales pertenecientes a algunas bibliotecas públicas de la provincia. También con el propósito de contribuir, aunque sólo sea añadiendo unos granos de arena al inmenso mar de la información, a que los contenidos hemerográficos de interés local se puedan conservar garantizando su difusión, ya que su acceso presenta a menudo importantes dificultades.

Las publicaciones locales digitalizadas tratan de temáticas diver- 

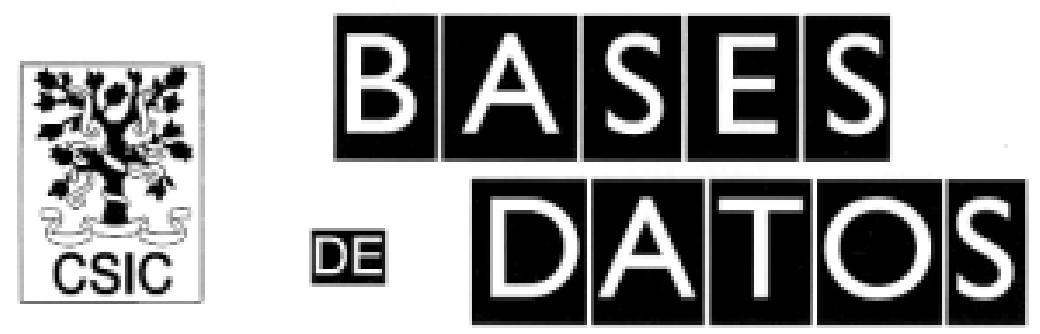

Consejo Superior de Investigaciones Cientificas

- CIRBICt Catálogo colectivo de Libros y Revistas existentes en las bibliotecas del CSIC. Su temática es nualtidisciplinar.

Volumen Libres: $1.400,000$

Volumen Revistas: 74000 Referescias

- ISOC: Base de datos referencial que recoge y analiza más de 1.600 revistas españolas relativas a Hamanidades y Ciencias Sociales. Se subdivide, según las distintas áreas ternáticas, en:

- ISOC - América Latina

- ISOC - Educación

- ISOC - Antropologia Social

- ISOC-Filcsofía

- ISOC-Arqueologia

- $150 \mathrm{C}$ - Geografia, Urbanismo y Arquitectura

- ISOC - Arte

- ISOC - Historia

- ISOC - Biblioteconomia y Documentación - ISOC - Lengua y Literarura

- ISOC - Derectho

- ISOC - Psicologí

- ISOC - Economía

- ISOC - Sociología y CC. Politicas.

Volumen: 450,000 Referencias

Crecimiento Anual: 35 Do0 Referencias.

- IME: Base de danos referencial que recoge y analiza más de 330 revistas móticas españolas.

Volumen: 210,000 Referencias

Creximiento Anual: 7.000 Referencias

- ICYT: Base de datos referencial que recoge y analiza más de 600 publicaciones periódicas españolas, dentro de los campos de la Ciencia y la Tecnología.

Volumen: 157.000 Referencias

Crecimiento Anual: 10.000 Referencias

- DATRI (Transferencia de resultudos de investigación de la Red OTRIOTTT).

Volumen: 8.000 Referencias

Crecimiento Anual: 1.500 Referencias

- Dates octubre 2003

- EN LínEa

- CD ROM

CENTRO DE INFORMACIÓN

$Y$ DOCUMENTACION CIENTIFICA (CINDOC)

UNIDAD DE DISTRIBUCIÓN DE BASES DE DATOS

Joaquin Costa, 22

28002 MADAID

Teléfono: $915635482 / 87 / 88$

Fax: 915642644

Correo electrónico: sdi@ cindoc.csic.es

Internet: http://www.cindoc.csic.es 
sas tales como arte, literatura, política y comercio, entre otras y abrazan un amplio período histórico que se remonta al siglo XIX; más concretamente entre 1869 y 1998.

\section{Fases del proyecto de digitalización}

El objetivo desde el inicio fue doble: por un lado la voluntad de preservación de las publicaciones locales originales y por otro, poner accesibles los textos hemerográficos de interés local depositados en las bibliotecas públicas de la Red de Bibliotecas Municipales de la Provincia de Barcelona. Sin haberlo previsto demasiado, y con la perspectiva que ahora tenemos, observamos que el proyecto se ha ido desarrollado en tres fases bien diferenciadas.

En la primera etapa, de acuerdo con la tecnología disponible en el momento, sólo se previó digitalizar las colecciones seleccionadas, almacenarlas en cd-rom e instalarlas en una torre de acceso compartido entre todas las bibliotecas de la red, a la cual se accedía a través de una línea frame relay.

Con posterioridad se da una vuelta de tuerca al proyecto, persiguiendo un fin más ambicioso: hacer posible la accesibilidad a los títulos a través de internet y, por lo tanto, dar acceso libre a todos los ciudadanos del mundo a través de una interfaz única. De acuerdo con las nuevas especificaciones técnicas se empieza a trabajar en la reestructuración de los datos ya digitalizados y también se amplía el proyecto con la inclusión de nuevos títulos.

Finalmente, en la tercera y última fase se diseña la interfaz web y, en mayo de 2003, se ponen a disposición del público los primeros 30 títulos pertenecientes a 9 bibliotecas municipales de la provincia de Barcelona, accesibles desde la página web del Servicio de Bibliotecas de la Diputación de
Barcelona. En enero de 2004 se posibilita la consulta a través de internet de la totalidad de los títulos digitalizados.

\section{Un poco de historia}

Nos situamos en el primer trimestre de 1999. Como decíamos, en un primer momento se decidió que las imágenes digitalizadas se almacenaran en cd-rom para su instalación en una torre de acceso compartido entre todos los centros de la red; con la voluntad clara de disponer de un programa informático para acceder a la información que solucionara las búsquedas (por materia, por texto libre, etc.) de manera fácil y rápida.

\section{«La Diputación de Barcelona inició en 1999 un proyecto de digitalización de re- vistas, diarios y bole- tines de los documen- tos originales perte- necientes a algunas bibliotecas públicas de la provincia»}

Trabajando a tres bandas, entre los bibliotecarios responsables del proyecto, los informáticos de la propia corporación y la empresa Tecnodoc S. A. (Tecnologías de la Documentación) empezamos con la digitalización de la publicación de la biblioteca central de Igualada: Vida... (1946-1998), que supuso 35.315 caras documentales, ocr (reconocimiento óptico de caracteres) y 24 cd-roms de salida y del ocr de 140.000 imágenes de 103 títulos más, ya digitalizados por la Fundación La Caixa, ya que se trataba de colecciones que procedían de la antigua biblioteca de dicha entidad en Igualada. Para dar valor añadido a la recuperación de la información incorporamos el programa de gestión documental de Tecnodoc, que permitía la consulta por título, fecha y texto libre.
En mayo de 2000 propusimos a la empresa Aragonesa de Digitalización $S$. L. la digitalización de los más de 55 volúmenes encuadernados, unas 22.000 páginas de la revista La moda elegante (18421927), de la biblioteca Francesca Bonnemaison de Barcelona. El producto resultante ocupó $6 \mathrm{~cd}$ roms, 19.250 páginas en blanco y negro y 2.750 páginas en color.

Por aquellas fechas, Aragonesa de Digitalización ya disponía de un gestor documental llamado Exipnos, que ofrecía búsqueda en texto libre sin límite de texto y que junto con las cabeceras indizadas, se convertía en una herramienta bastante rápida en la localización de las páginas. Además, durante ese período habían diseñado una versión en catalán para introducirse en el mercado de Cataluña; pero en el año 2000 el Exipnos catalán aún estaba en un estadio bastante inicial. La empresa dejó el programa abierto para que los propios bibliotecarios pudieran añadir texto y algunos comentarios de manera que se pudiera ir completando la indización de la revista.

Así se empezó a llevar a cabo la indización mediante un tesauro creado por los bibliotecarios del equipo de la biblioteca Francesca Bonnemaison, con la idea de ir asignando palabras clave a todas las imágenes que aparecían en la publicación. Esta metodología se abandonó más adelante debido al enorme volumen de trabajo que iba presentando. En septiembre de ese mismo año ya pudimos realizar pruebas en nuestro servidor instalando los CDs y el programa de consulta.

Durante el año 2001 el Servicio de Informática y Telecomunicaciones de la Diputación de Barcelona, viendo la envergadura e importancia del proyecto de digitalización iniciado por el Servicio de Bibliotecas, decide participar activamente en el mismo a través de la Uni- 
dad de Tratamiento Gráfico y Documental, sección experta en llevar a cabo los proyectos de digitalización de la corporación. Nuevamente se contrató a Aragonesa de Digitalización para la digitalización de 3 títulos más de la biblioteca Francesca Bonnemaison de Barcelona: Feminal (1907-1909) -2.624 páginas en color, 5 cd-roms-; Le style parisien (1916) —66 páginas en color, 2 cd-roms-y Les elegances parisiennes (1916-1923) -2.244 páginas en color, 6 cdroms-

Se definen las especificaciones técnicas que detallan la estructura general de la información, las características de las imágenes y la grabación de los datos indizados. Se propone a las dos empresas con las que se ha trabajado que realicen sólo el proceso de digitalización y elaboren un cd de prueba para verificar si han seguido correctamente los requisitos exigidos pidiéndoles que reestructuren los datos almacenados de acuerdo con estas nuevas especificaciones.

El presupuesto de 2002 incluye una partida dedicada al proyecto de digitalización (21.943,67 euros) y se solicita el presupuesto a Tecnodoc de 8 cabeceras más de 5 bibliotecas. Ese mismo año se encargan también 31 títulos más pertenecientes a otros 6 centros. Se cambia la estructura de toda la documentación digitalizada de la biblioteca central de Igualada y se graba la información en soporte dvd; esto conlleva una mejora de espacio importante ya que se pasa de más de 200 cd-roms a sólo 20 dvds.

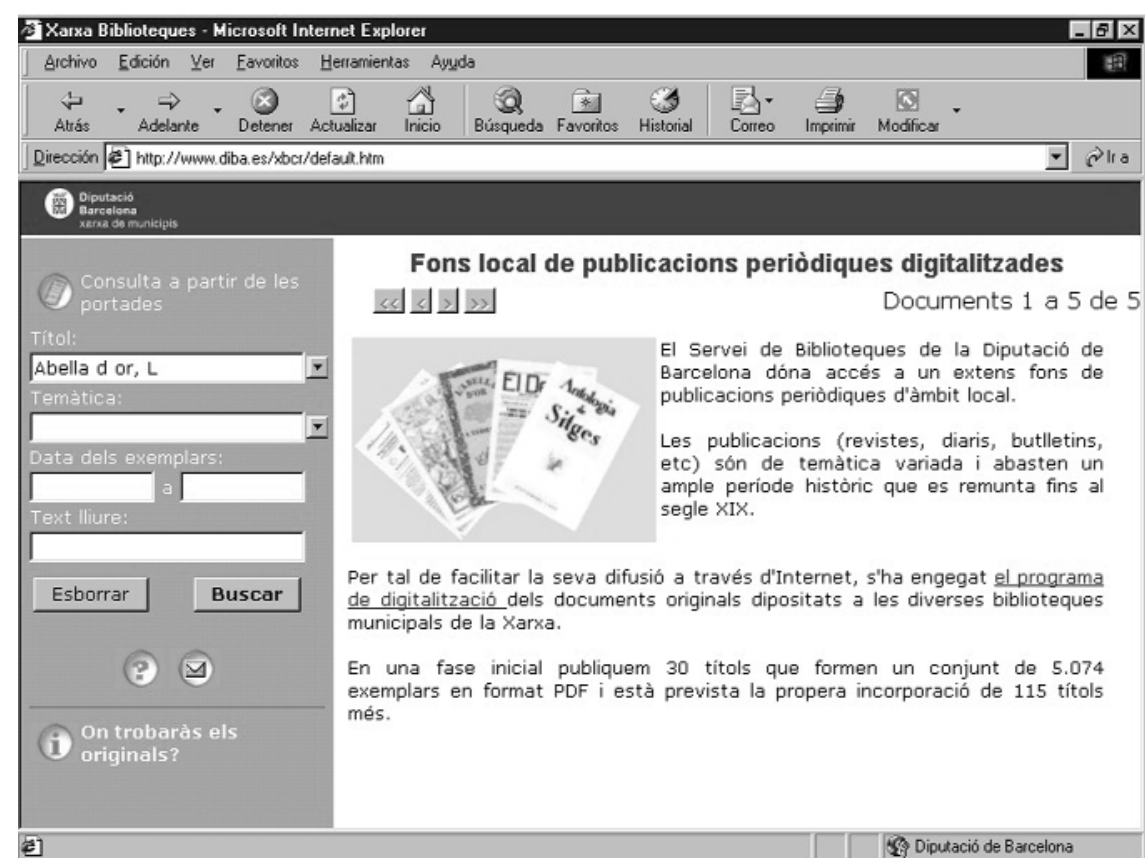

Figura 1

La empresa FemFum.com se encarga de desarrollar un programa para generar en masa colecciones de publicaciones en formato pdf a partir de imágenes tiff/jpeg y de los textos almacenados en soporte cd/dvd. El diseño del programa finaliza en diciembre de 2003.

Paralelamente a la nueva reestructuración de los datos, se solicita a la empresa Tecnodoc la conversión de todos los cd-roms en dvds. También se le pide a Aragonesa de Digitalización que haga lo mismo con los títulos que había digitalizado. Es evidente que con el cambio de soporte de almacenamiento se reduce considerablemente el número de volúmenes.

Se empieza a elaborar la interfaz web para la consulta de la colección hemerográfica y finalmente, alcanzando el objetivo perseguido durante unos cuantos años de trabajo, en mayo de 2003 se po-

\begin{tabular}{|r|r|r|r|}
\hline Año & Tecnodoc S. L. & $\begin{array}{r}\text { Aragonesa de } \\
\text { Digitalización S. A. }\end{array}$ & \multicolumn{1}{|c|}{ Totales } \\
\hline 2000 & $7.493,58$ euros & $12.019,63$ euros & $19.507,21$ euros \\
\hline 2001 & 0,00 euros & $5.403,97$ euros & $5.403,97$ euros \\
\hline 2002 & $21.943,67$ euros & 0uros & $21.943,67$ euros \\
\hline & $29.437,25$ euros & $17.414,60$ euros & $46.851,85$ euros \\
\hline
\end{tabular}

ne a disposición de los ciudadanos el acceso público de los primeros 30 títulos de revistas digitalizadas de 9 bibliotecas municipales de la provincia, accesibles desde la web del Servicio de Bibliotecas o directamente desde la url específica del proyecto (figura 1 ).

http://www.diba.es/biblioteques/ini ci.asp

http://www.diba.es/xbcr/default.htm

Estos trabajos suponen un número aproximado de 5.074 ejemplares y 30.000 páginas en formato pdf. En enero de 2004 se amplían los títulos disponibles a través de internet y finaliza así la incorporación del resto de la colección hemerográfica digitalizada, un total de 143 títulos, 270.000 páginas y 30.000 ejemplares.

\section{Proceso de trabajo}

\section{Presupuesto.}

La voluntad clara del Servicio de Bibliotecas en relación con la digitalización de fondos hemerográficos locales se pone de manifiesto en la previsión y dotación del presupuesto necesario anual donde este proyecto tiene un peso específico. Con el visto bueno del mismo por el Área de Cultura de la corporación, y posteriormente su 
aprobación por el Pleno de la $D i$ putación de Barcelona se pone en marcha el engranaje del proceso de trabajo (tabla 1).

La previsión de la partida de digitalización para el 2004 es de 50.000 euros, una cantidad que no sólo iguala la inversión total que se ha realizado desde el inicio del proyecto, sino que la supera en más de un $6,7 \%$.

\section{Selección de la colección a digitalizar.}

Algunas de las bibliotecas que forman parte de la red gozan de gran tradición histórica y tienen publicaciones periódicas locales de mucho valor hemerográfico. Para la selección de los títulos se establecen unos criterios básicos, que son: el interés de la publicación, ya que puede ser una colección única o de gran interés para los estudiosos del tema que trata; su estado físico, en cuanto a que su nivel de deterioro sea muy grande para dejar que los ciudadanos la consulten físicamente; también se tiene en cuenta el hecho de que esté completa, es decir, que se conserve la totalidad de sus números. Y por último, otro aspecto importante, es el hecho de que los derechos de autor ya no estén vigentes.

Con la ayuda de los directores de las bibliotecas se realiza una prospección entre los centros que disponen de colecciones susceptibles de adecuarse a estos criterios y se les pide que identifiquen los títulos y enumeren por orden de prioridad los considerados más importantes.

Se les envía una ficha técnica para que de cada título rellenen algunos datos útiles como: título de la publicación, prioridad, período, intervalo de años, formato (octavo, cuarto, folio, g-folio, etc.), total de tomos (en el caso que estén cosidos se debe contar los que hay en cada volumen), total de volúmenes (si están cosidos), total de ejemplares

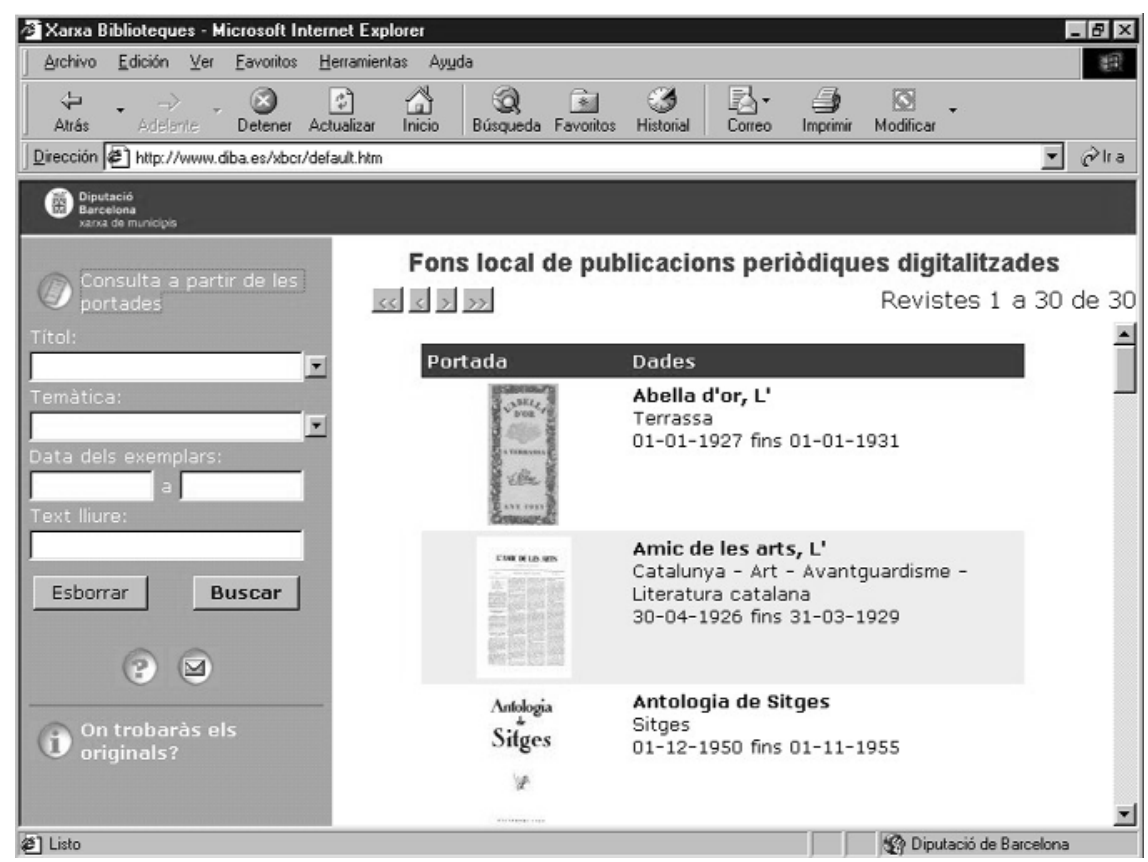

Figura 4

(si son números de revista sin coser), posibilidad de desencuadernarlos fácilmente (o no), estimación de número de páginas por ejemplar, estimación de número de páginas en color y en blanco y negro, número de anexos.

Con toda la información recogida se evalúa la prioridad e interés de cada título y se realiza la selección. Debemos agradecer la colaboración de todos los directores de las bibliotecas que, con la experiencia y el conocimiento del uso e interés que despiertan los diferentes títulos de su colección, han ido participando en el proyecto. Sin su ayuda no habría sido posible llevar a cabo un trabajo de esta envergadura.

Además, se incluyeron también aquellas cabeceras que algunas bibliotecas, con presupuesto económico de su ayuntamiento, ya se habían digitalizado. No obstante, no seguían las especificaciones técnicas necesarias y no eran susceptibles de ser consultadas a través de internet. Era una lástima no aprovechar la digitalización y ocr existentes, así que se decidió incluir algunos títulos y adaptarlos a los requisitos exigidos y reestructurarlos, como por ejemplo las ca- beceras de la biblioteca central de Igualada (figura 4).

\section{Derechos de autor y cesión de los mismos.}

Con el objetivo final de poner a disposición del público en general el libre acceso a la colección digitalizada a través de internet, hay que tener en cuenta otro factor de suprema importancia: los derechos de autor y cesión de los mismos. Por lo tanto, previo a la digitalización del material, se procede a investigar si las publicaciones tienen derechos de autor aún vigentes.

De los 143 títulos digitalizados en esta primera etapa, sólo 3 tienen propiedad de los derechos sobre su edición. Para obtener permiso sobre el libre acceso a esas cabeceras, el Servicio de Bibliotecas pide a los propietarios de los derechos que autoricen a la Diputación de Barcelona la reproducción y comunicación pública en formato electrónico accesible a través de internet.

La autorización es válida durante 5 años, renovable por un mismo período a excepción que alguna de las partes la rescinda. De momento los propietarios están de acuerdo en autorizar el uso a través 


\section{Gestión de recursos} digitales audio, video, imagen y texto

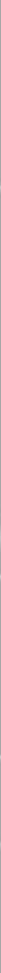

DigiTool es un sistema de explotación de fondos

digitales que le proporciona todas las

herramientas necesarias para la creación,

archivo, indexación, búsqueda, gestión y

visualización de colecciones digitales.

Ex Libris
Oficina Central:

Tuset 19, $2^{2 .} 7^{*} 08006$ - Barcelona Tel: 902118398 Fax: 932021077

Delegación:

Jaen, 15 28020- Madrid

Tel: 902196032 Fax 915711952

www.greendata.es 
de internet puesto que consideran (igual que los bibliotecarios) que representa un valor añadido para la publicación original.

\section{Selección de la empresa di- gitalizadora.}

Hasta el momento solamente hemos trabajado con dos empresas de digitalización. Tuvimos contacto con ellas a partir de sus representantes comerciales que se dieron a conocer personalmente en las oficinas del Servicio de Bibliotecas. Apreciamos la política de actuación y los servicios que ofrecían ambas y decidimos contratarlas.

Hasta ahora hemos contratado sus servicios mediante una adjudicación directa debido a que el importe de cada mini proyecto no superaba los 12.000 euros. Para 2004, la Diputación de Barcelona ha aprobado la cantidad de dinero propuesta por el Servicio de Bibliotecas (50.000 euros ), $\mathrm{y}$ por lo tanto la inversión de la nueva etapa del proyecto de digitalización se adjudicará por concurso público.

El procedimiento utilizado hasta la fecha ha sido el siguiente: una vez seleccionados los títulos,

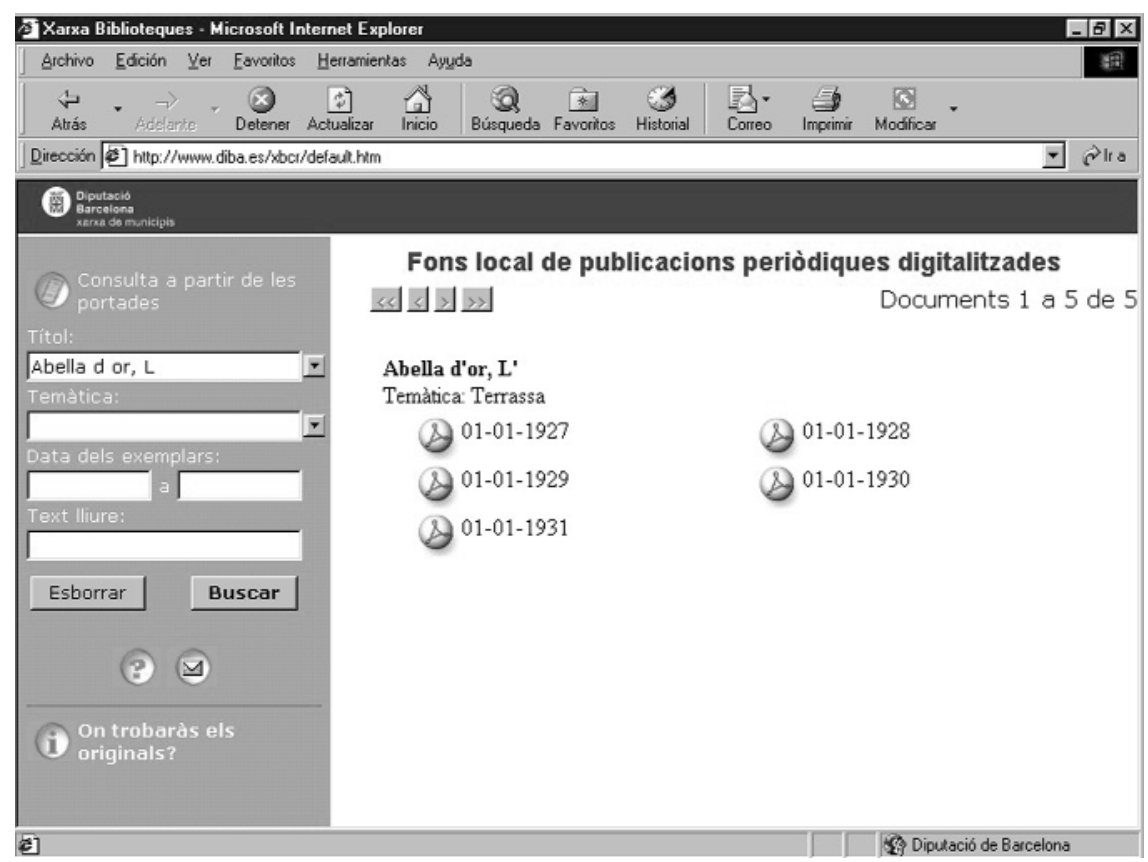

Figura 2

la empresa elabora un presupuesto orientativo en función de las cabeceras y sus características. Habitualmente se desplaza un responsable de la misma a las bibliotecas para ver las colecciones $y$, una vez in situ, comprueba su estado y puede precisar más detalladamente el presupuesto.

5. Memoria para las adjudicaciones directas.

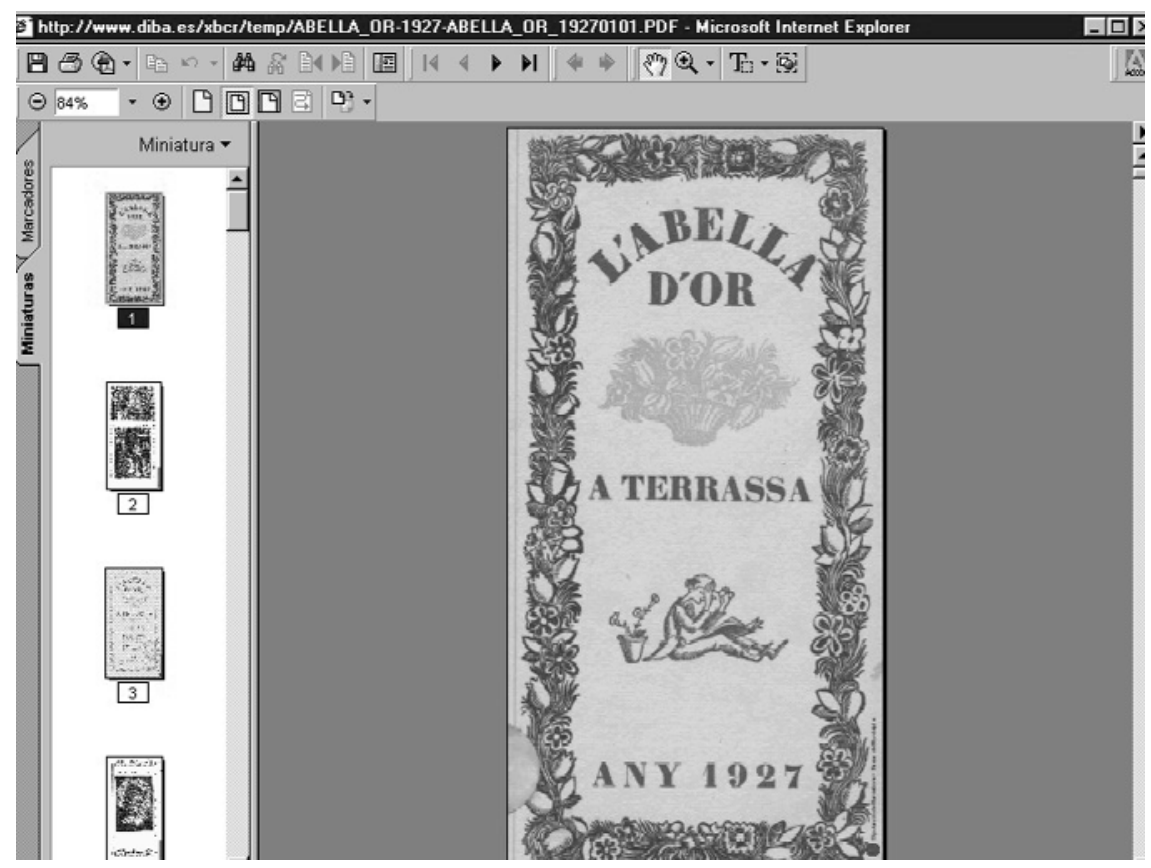

Figura 3
Para tramitar la adjudicación directa del proyecto ha sido necesaria la elaboración de una memoria redactando los motivos por los cuales se considera de gran importancia llevar a cabo este trabajo de digitalización, especificado el propósito del proyecto y su justificación económica. Además, se ha adjuntado la relación y las características de los títulos a digitalizar.

\section{Recogida de los materiales.}

Una vez en este punto del proceso, con el presupuesto aprobado y los títulos seleccionados, se procede a la recogida de los materiales; por lo que respecta al transporte, tanto de ida como de vuelta, se encarga la propia empresa. El personal de las bibliotecas prepara el material y lo etiqueta debidamente para facilitar su identificación en las sedes centrales de las empresas (Madrid y Zaragoza respectivamente). Una vez las colecciones físicas han sido digitalizadas, éstas se devuelven a las bibliotecas propietarias.

\section{Especificaciones técnicas.}

El cambio de la idea inicial de guardar toda la información en cdrom para luego instalarla en una torre de acceso compartido, por la de 


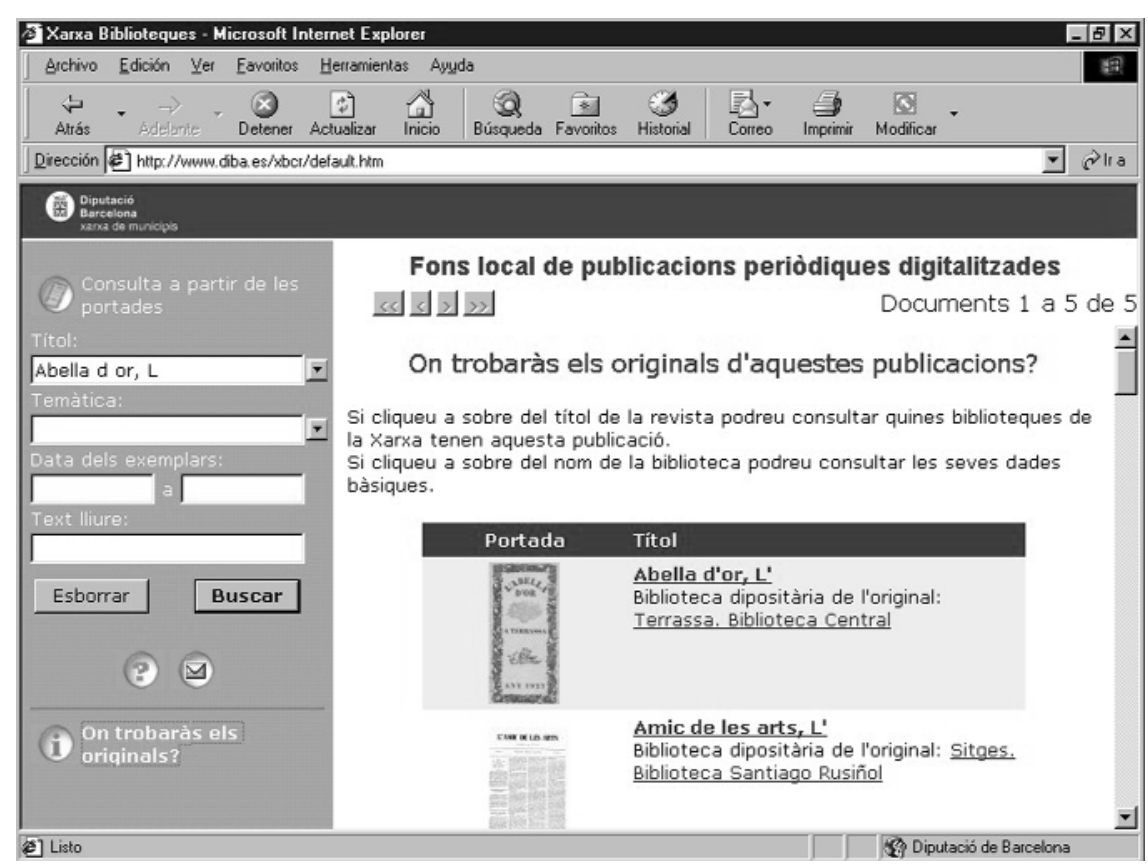

Figura 5

poner las colecciones digitalizadas de acceso libre a través de internet obligó a disponer de un servidor web con espacio suficiente para albergar todos los datos y la estructura de los mismos puesto que la consulta se llevaría a cabo a través de una interfaz web. Al principio, y antes del cambio de orientación, las dos empresas realizaron todo el proceso de la digitalización de las publicaciones, escaneo, ocr, estructuración de los datos y almacenamiento de los mismos en soporte cd-rom.

En el momento que la Unidad de Tratamiento Gráfico y Documental del Servicio de Informática y Telecomunicaciones se encargó de los trabajos técnicos del proyecto de digitalización, propuso un cambio en el método de trabajo de las empresas y en la estructura de la información almacenada. Se acuerda que las empresas sólo digitalicen (con ocr incluido) y almacenen los datos según una estructura rígida a partir de nuestras especificaciones técnicas. Esto conlleva que todo el trabajo hecho hasta entonces deba reestructurarse de nuevo, lo que añade también un incremento económico. A cada uno de los títulos, los expertos en catadiseñara un programa de conver- sión automática de las imágenes. Una vez la aplicación estuvo acabada se empezó la conversión, imagen a imagen.

Pdf es el formato utilizado para la difusión y, de acuerdo con las recomendaciones internacionales, a nivel de preservación y conservación, disponemos de las imágenes tiff/jpeg y de los textos almacenados en soporte cd-rom o dvd (una copia, la master, está disponible en las sedes de las empresas colaboradoras y otra en la Diputación de Barcelona).

\section{Interfaz de consulta.}

Una vez acabado todo el proceso se efectúa el volcado de la información en un servidor web. Preparamos una interfaz amigable para acceder a los fondos y realizar búsquedas, la cual permite la consulta por título de la revista, por materia, por texto libre y por fechas de publicación. Asimismo se puede consultar a partir de un listado de las portadas de las publicaciones donde se relaciona el título, las fechas y las materias asignadas. Una vez obtenidos los resultados, se visualizan los ejemplares mediante el programa de visualización Adobe Acrobat (cada ejemplar consta de varias páginas en formato pdf) lo que permite realizar, además, consulta por texto libre dentro del ejemplar mismo. Existen, pues, dos tipos de búsqueda: por ejemplar y dentro del mismo (figuras 2 , 3 y 5 ).

\section{Hacia dónde vamos}

La perspectiva de cara a un futuro inmediato es ofrecer un modelo de biblioteca que integre los servicios y los recursos centrados en el usuario. Esto conlleva el acceso integrado de recursos y servicios en una misma interfaz. Así que, además de apostar por la digitalización de las colecciones únicas de las bibliotecas, como hemos empezado a hacer con este proyecto, debemos aumentar la colección elec- 
trónica y las suscripciones de recursos electrónicos de acuerdo con las necesidades informativas de los ciudadanos para ampliar la oferta de servicios virtuales.

Y, por supuesto, desde la faceta de la biblioteca digital favorecer que la totalidad de la colección digitalizada (lo presente y lo que se haga de ahora en adelante) esté integrada en el catálogo colectivo de la Xarxa de biblioteques municipals de la provincia de Barcelona. Gracias a la integración total de las diferentes bases de datos, con una sola búsqueda se podrá acceder a la totalidad de los registros que forman las diferentes colecciones de las bibliotecas, sean documentos electrónicos a texto completo, referencias bibliográficas o documentos en otros formatos.

Glòria Pérez-Salmerón y Anna M. Surroca Carrera, Servicio de Bibliotecas de la Diputación de Barcelona. perezsg@diba.es

surrocacm@diba.es 